\title{
Role of Interleukin-18, S-adenosylmethionine and S- Adenosylhomocysteine as Cardiovascular Risk Factors in Patients with Systemic Lupus Erythematosus
}

\author{
Ayman Z. El Samanoudy ${ }^{1}$, Adel Zalata ${ }^{1}$, Abd El Hameed A Metwali ${ }^{2}$, \\ Fayez el Kenawy ${ }^{2}$ and Adel Elbadrawy ${ }^{3}$ \\ Departments of Medical Biochemistry ${ }^{1}$, Internal medicine ${ }^{2}$, and \\ Diagnostic Radiology ${ }^{3}$, Faculty of Medicine, Mansoura University
}

\begin{abstract}
Background: The incidence of Systemic Lupus Erythematosus (SLE) appears to be increasing and the main cause of death in that disease is coronary artery disease since SLE is associated with premature atherosclerosis. The association of plasma interleukin-18 levels and proinflammatory cytokines with cardiovascular risk in SLE patients has not been extensively established. Hyperhomocysteinemia is associated with increased risk for cardiovascular events, but it is not clear whether it is a marker or mediator for vascular dysfunction or a marker for another risk factor. Aim of the work: The purpose of the present study was to determine whether plasma IL-18, SAM, SAH and SAM/SAH ratio are associated with cardiovascular risk factors and disease activity in SLE patients. Subjects and Methods: The plasma concentrations of a novel pro-inflammatory cytokine, interleukin (IL)-18 by ELISA as well as SAM,SAH and SAM/SAH ratio by HPLC was determined in 31 patients with systemic lupus erythematosus (SLE) and 30 sex- and age-matched healthy control subjects and correlated them with cardiovascular risk factors and the SLE disease activity. For every patient the systemic lupus disease activity was assessed using the Systemic Lupus Erythematosus Disease Activity Index (SLEDAI). Body mass index (BMI), systolic blood pressure, diastolic blood pressure, CBC, liver functions, plasma creatinine, urine analysis, erythrocyte sedimentation rate (ESR)1, ANA, anti-ds DNA, C3, C4, fasting insulin and glucose, plasma lipid profile, plasma SAH,SAM ,SAM/SAH ratio, titers of autoantibodies against oxidized low-density lipoprotein and carotid intima media thickness (CIMT) were determined. SLE patients with a history of diabetes mellitus, hypertension, hyperlipidemia, smoking, or coronary artery disease (CAD) and positive pregnancy test were excluded. Results: The mean age of $S L E$ patients was $35.1 \pm 10.3$ years and the mean duration of SLE was $4.2 \pm 2.9$ years. Plasma concentrations of IL-18 were significantly higher in SLE patients than agematched healthy controls $(p<0.001)$. Also, plasma SAH is elevated in SLE patients versus controls while SAM and SAM/SAH ratio were significantly lower in SLE patients versus controls. Elevation of plasma IL-18 correlated positively and significantly with SLE disease activity index. In addition, plasma concentrations of IL-18 correlated positively and significantly with BMI, insulin, Homeostasis model assessment insulin resistance (HOMA IR), triglycerides, CIMT, and SAH, in SLE patients. IL18 concentrations showed a positive and significant correlation with
\end{abstract}


plasma creatinine $(r=0 \cdot 7, P=0 \cdot 001)$, antinuclear antibody (ANA) $(r=0.6, p=0.001)$, anti double stranded DNA (dsDNA) $(r=0.5, p=0.008)$, ESRI $(r=0.56, p=0.001)$. The concentrations of plasma IL-18 in SLE patients with elevated plasma creatinine were significantly higher than those with normal plasma creatinine $(285.7 .6 \pm 59.6 \mathrm{pg} / \mathrm{ml} \mathrm{vs}$ 182.8 29.4, $p<0.001)$. Also, SLEDAI correlated positively with both plasma levels of insulin and HOMA-IR values ( $p<0.05$ in both). Conclusions: In SLE patients, a high $I L-18$ level reflects activity of the disease and is related to cardiovascular risk factors. IL-18 is therefore suggested to play a crucial role in triggering the inflammatory processes of premature atherosclerosis in SLE, in addition to the markers of disturbed homocysteine metabolism could play a role as mediator of cardiovascular disorders in SLE.

Key words: IL 18, SAH/SAM ratio, Systemic Lupus Erythematosus, Disease activity, atherosclerosis, T-helper cell cytokines

\section{INTRODUCTION}

Systemic lupus erythematosus (SLE) is a systemic chronic inflammatory disorder characterized by a wide range of immunological hyperactivity, autoantibody production and multi-organ damages ${ }^{(1)}$.

Women with SLE have been demonstrated to have 50 -fold increased risk of developing myocardial infarction than women in general population. The relative risk for coronary heart disease has been still 7 to 17 -fold higher, even after adjusting for traditional risk factors in $\mathrm{SLE}^{(2)}$. Therefore, these reports have suggested that patients with SLE possess excess risks over the traditional risk factors for the development of accelerated atherosclerosis, and these risk factors might be metabolic changes like lipoprotein oxidation, insulin resistance, hyperhomocysteinemia and vascular stiffness which may also significantly contribute to the pathogenesis of cardiovascular disease $^{(3)}$.
Cytokines play an important and diverse role in the pathogenesis of lupus. There are a variety of hypothetical explanations for cytokine imbalances in that disease. Considerable attention has been given to the Th1/Th2 model as well as to combinations of pro- and antiinflammatory mediators ${ }^{(1)}$.

Interferon- $\gamma$ (IFN- $\gamma$ ) is the classic Th1 cytokine. Its expression is regulated by a number of IFNinducing monokines, such as IL-12, IL-18, and IL-15. Elevated serum levels of IL-12,IL-18, and IFN- $\gamma$ have been observed in patients with active lupus ${ }^{(4)}$. Also, IL 18, make atherosclerotic lesions in SLE more prone to rupture than in 'normal' atherosclerosis ${ }^{(5)}$.

Elevation of plasma concentration of total homocysteine (tHcy) is considered to be a clinical risk factor for cardiovascular disease ${ }^{(1-3)}$. Mild or moderate hyperhomocysteinemia (plasma tHcy concentration of 15 to $50 \mathrm{mmol} / \mathrm{L}$ ) is found in up to $40 \%$ of patients with myocardial infarction, stroke, or venous thrombosis ${ }^{(\boldsymbol{(})}$, and it may contribute to the pathogenesis of cardiovascular diseases in $\mathrm{SLE}^{(7)}$. 


\section{Aim of work}

To evaluate the relationship of interleukin 18 concentrations as well as SAH,SAM and SAM/SAH ratio to some cardiovascular risk factors in patients with Systemic Lupus Erythematosus (SLE) and to evaluate their possible clinical significance with the disease activity.

\section{PATIENTS \& METHODS}

The current study was carried out on 31 patient with SLE (27 female and 4 males) selected from the Rheumatology and Immunology Outpatient and Inpatient Clinic at Mansoura University Hospitals, Internal Medicine Department. Thirty, sex- and age-matched healthy volunteers were recruited as controls.

All patients fulfilled four or more of the American College of Rheumatology revised criteria for diagnosis of $\mathrm{SLE}^{(\mathbf{8})}$.

SLE patients with a history of diabetes mellitus, hypertension, hyperlipidemia, smoking, or coronary artery disease (CAD) and positive pregnancy test were excluded.

The systemic lupus disease activity was assessed using the Systemic Lupus Erythematosus Disease Activity Index (SLEDAI). SLEDAI was developed by the consensus experts a global assessment of lupus disease activity. Points are based on a weighted index for lupus disease activity with 8 points for central nervous and vascular systems, 4 points for renal and musculoskeletal system, 2 points for serosal, dermal and immunological systems, 1 point for constitutional and hematologic parameters. The points are assigned if the descriptor is present at the time of the present visit or within the preceding 10 days. Mild to moderate disease is associated with SLEDAI scores $\leq 10$ and SLEDAI scores $>10$ are associated with greater disease activity. In the present study any value above 4 was considered active disease $^{(9)}$. Study subjects underwent full history taking and thorough physical examination. The BMI of each patient was calculated as the weight in kilograms divided by the square of height in meters. Blood pressure was measured, laboratory investigations: urine analysis.

Especially for proteinuria, RBCS casts, complete blood count, liver functions, serum creatinine, ESR by westergreen method, antinuclear antibody (ANA) by ELISA ${ }^{(\mathbf{1 0})}$, anti double stranded DNA antibodies (anti- ds DNA) by ELISA ${ }^{(11)}$, and complement $\mathrm{C} 3$, and $\mathrm{C} 4$ were determined by radial immunodiffusion technique $^{(\mathbf{1 2})}$.

\section{Estimation of plasma IL 18 concentrations:}

Plasma IL 18 concentrations of SLE patients and controls were measured by enzyme-linked immunosorbent assay (ELISA) using the human bioactive IL-18 ELISA kit (Medical \& Biological Laboratories Co., Ltd., Nagoya, Japan). The concentration of human IL-18 was calculated from a dose response curve based on reference standards provided by the kit ${ }^{(13)}$

Separation of S-adenosylmethionine and S-adenosylhomocysteine by high performance liquid chromatography (HPLC) ${ }^{(14)}$ :

Plasma was mixed 1:2 with $0.4 \mathrm{M}$ $\mathrm{HClO} 4$ for 30 minutes and centrifuged 
at $10000 \mathrm{~g}$ for $15 \mathrm{~min}$ at $4^{\circ} \mathrm{C}$; the supernatant was filtered through a $0.2-$ $\mathrm{mm}$ poly-propylene syringe filter $(0.4$ $\mathrm{mm}$ diameter, Whatman, Clifton, NJ, USA). A $20 \mu$ l aliquot of the acid extract was applied directly onto the HPLC. SAM and SAH standards (Sigma, St. Louis, MO, USA) were dissolved in water at a concentration of $1 \mathrm{mM}$ and then diluted with $0.4 \mathrm{M}$ $\mathrm{HClO} 4$ to the final concentration used during HPLC analysis. Aliquots of 20 $\mu \mathrm{l}$ of standard solutions containing 50 -11000 pmol were injected onto the HPLC. Hewlett Packard HPLC model 1984 B equipped with variable UV detector (Hewlett Packard, 1050 series, USA) adjusted at wavelength
$254 \mathrm{~nm}$ was used. The separation was done on reversed phase (RP $18 \mathrm{C}$ Lichrosorb, $15 \mathrm{~cm}$ - $4.6 \mathrm{~mm}$ i.d., Hibar, Merck, Darmastadt, Germany) column. The mobile phase consisted of $40 \mathrm{mM}$ NH4H2PO4, $8 \mathrm{mM} 1-$ heptanesulfonic acid (Sigma,St. Louis, MO, USA)., and 18\% (v/v) methanol (HPLC grade), $\mathrm{pH}$ adjusted to 3.0 with $\mathrm{HCl}$. HPLC analyses were conducted at a flow rate of 0.7 $\mathrm{ml} / \mathrm{min}$. HPLC was performed at room temperature. Quantification was based on integration of peak areas and compared to the standard calibration curves of SAM and SAH (Fig. 1). The results are expressed in nmol /L.

Figure1: HPLC Chromatogram of standard mixture of SAM, and SAH:

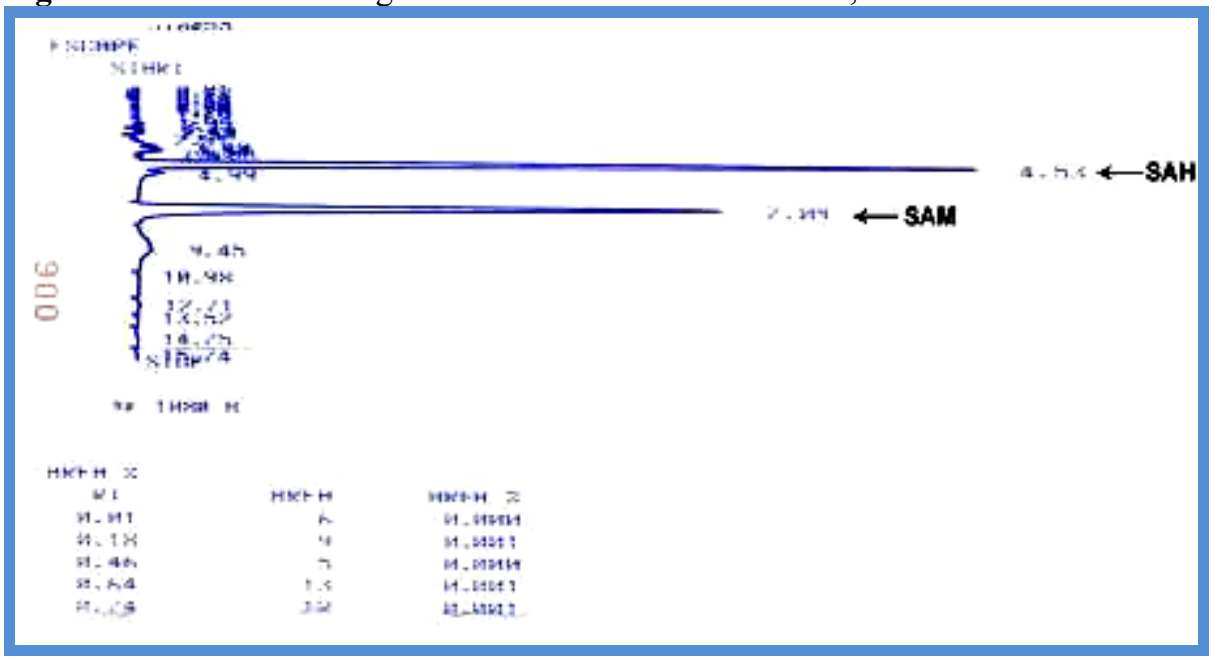


Estimation of fasting blood glucose, insulin and lipid profile

The fasting glucose concentration was determined using an enzymatic colorimetric method (Sigma Chemical Company, St Louis, MO, USA). Fasting insulin concentrations was conducted using an Abbott IMx Insulin Kit based on a microparticle enzyme immunoassay (MEIA) (Abbott Laboratories, Dainabot, and Tokyo, Japan). Homeostasis model assessment insulin resistance (HOMA IR) and HOMA B-cell were calculated according to the formulae in the HOMA model ${ }^{(15)}$.

Enzymatic methods were used to determine plasma concentrations of total cholesterol (Beckman TC Reagent) ${ }^{(\mathbf{1 6})}$, and triglycerides (Beckman TG Reagent) ${ }^{(17)}$, and highdensity lipoprotein-cholesterol (HDLC) ${ }^{(\mathbf{1 8 )}}$. Low-density lipoproteincholesterol (LDL-C) was determined by the Friedewald equation ${ }^{(19)}$. Susceptibility of LDL to oxidation was determined according to titres of autoantibodies against oxidized LDL (ox-LDL) using an ImmuLisaTM Anti-oxLDL Antibody ELISA Kit (IMMCO Diagnostics, Buffalo, NY, USA).

Carotid IMT of the common carotid artery was determined using duplex ultrasonography with a highresolution 7.5-MHz transducer (SSA380A; Toshiba, Tokyo, Japan). Carotid IMT was defined as the distance from the leading edge of the first echogenic line to the leading edge of the second echogenic line in the sonographic image. Measurements of IMT were made at each of the three sites of the greatest thickness on both sides. Carotid IMT was defined as the mean of these maximal IMT measurements $^{(\mathbf{2 0})}$.

\section{Statistical analyses}

Data were collected, revised, verified then edited on personal computer and then analyzed using the Statistical Package of Social Sciences (SPSS) version 10 for Windows (SPSS, Inc., Chicago, IL, USA). Data were presented using mean and standard deviation (SD) for all quantitative values and or number of cases (percentage) for qualitative values.

The distribution of tested variables was examined graphically for normality. Pearson's correlation analysis was used to examine the relationships between plasma IL-18 and tested cardiovascular risk factors. Receiver Operating Characteristic (ROC) graph analysis for plasma IL18 and SAM/SAH ratio in order to quantitate and assess its diagnostic performance in differentiation between SLE patients and control subjects. $\mathrm{P}$ values $<0.05$ were considered significant for all statistical analyses in the present study.

\section{RESULTS}

The study populations comprised 31 patients with SLE with a mean age of $35.1 \pm 10.3$ years and 30 control subjects with a mean age of $33.4 \pm 9.6$ years. Patients with SLE and control subjects were well matched with respect to age, gender and BMI. The mean SLE disease duration was $4.2 \pm 2.9$ years (range from 0.2 to 10 years).

The concentrations of plasma IL18 in SLE patients were significantly higher than those in control subjects 
(222.6 $\pm 66.5 \mathrm{pg} / \mathrm{ml}$ versus $133.4 \pm 44.2$, $\mathrm{p}<0.001)$.

The plasma concentration of SAM is statistically significantly lower in SLE patients than the control group $(86.1 \pm 10.2 \quad$ versus 116.1 $\pm 26.9, \mathrm{p}<0.001$ ), the plasma $\mathrm{SAH}$ concentration shows statistically significant increase in SLE patients than the controls $(34.7 \pm 7.8$ versus $23.8 \pm 6.9, \mathrm{p}<0.001)$, consequently the $\mathrm{SAM} / \mathrm{SAH}$ ratio shows statistically significant decrease in SLE patients than the controls $(2.65 \pm 0.94$ versus $5.24 \pm 1.8 \mathrm{p}<0.001)($ table, 1$)$

However, there was a significant positive correlation between IL-18 concentrations and SLEDAI score in SLE patients $(\mathrm{r}=0.449, \mathrm{P}=0.004)$ (figure 2).

There were significant positive correlation between plasma IL-18 concentrations and body mass index $(\mathrm{r}=0.45, \mathrm{p}=0.01)$, plasma levels of triglycerides $(\mathrm{r}=0.42, \mathrm{p}=0.02)$, fasting insulin $(r=0.54, p=0.002)$ and HOMAIR $\quad(\mathrm{r}=\quad 0.52, \mathrm{p}=0.003), \quad$ CIMT $(\mathrm{r}=0.22, \mathrm{p}=0.04)$.

No significant correlation was found between IL-18 concentrations and other cardiovascular risk factors (table 2).

There were significant positive correlation between plasma IL 18 concentrations and ANA $(\mathrm{r}=0.6, \mathrm{p}=0.001)$, Anti dsDNA $(\mathrm{r}=0.5$, $\mathrm{p}=0.008)$, ESR1 $(\mathrm{r}=0.56, \mathrm{p}=0.001)$ and serum creatinine $(\mathrm{r}=0.7, \mathrm{p}=0.001)$ (table 3).

The concentrations of plasma IL18 in SLE patients with elevated plasma creatinine were significantly higher than those with normal plasma creatinine $(285.7 .6 \pm 59.6 \mathrm{pg} / \mathrm{ml}$ versus $182.8 \pm 29.4, \quad \mathrm{p}<0.001 ; \quad 18.5 \pm 7.6$ ųmol/1 versus $12.8 \pm 3.7, p<0.001$ respectively), while, SAM/SAH ratio was significantly lower in patients with elevated plasma creatinine than those with normal plasma creatinine.

CIMT was significantly greater in SLE patients than in control subjects $(0.89 \pm 0.42$ vs. $0.59 \pm 0.11 \mathrm{~mm}$, $\mathrm{P}<0.0001) \quad$ (table 1). Plasma concentrations of IL-18 tended to correlate positively with mean CIMT $(\mathrm{r}=0.22, \mathrm{P}=0.04)$ (table 2$)$.

There was positive correlations between systemic lupus erythematosus disease activity index and both plasma levels of insulin and HOMA-IR values $(\mathrm{p}<0.05$ in both) (table 5).

Also, there was positive statistically significant positive correlation between plasma SAH concentration and BMI, IL-18 and plasma creatinine level, but it showed significant negative correlation with HDL-C, and fasting blood glucose level (table 4).

On the other hand, there was statistically significant negative correlation between plasma SAM concentration and triglycerides, IL-18, fasting plasma glucose and plasma creatinine level and there was significant negative correlation between $\mathrm{SAM} / \mathrm{SAH}$ ratio and $\mathrm{BMI}$, TG, HDL-C, IL-18, fasting blood glucose and plasma creatinine level.

Figure 3 shows Receiver Operating Characteristic (ROC) graph analysis for plasma IL-18 and $\mathrm{SAM} / \mathrm{SAH}$ ratio. The graph was applied in order to quantitate and assess its diagnostic performance in differentiation between SLE patients and control subjects. It revealed that the best cut off value of plasma IL-18 
was 3.7 as the diagnostic sensitivity was $70.3 \%$, specificity of $90.3 \%$. The area under the ROC curve was 0.83 (95\% confidence interval $0.75-0.94$, $\mathrm{p}=0.001)$ and $\mathrm{SAM} / \mathrm{SAH}$ ratio was 3.7 as the diagnostic sensitivity was 80.0 $\%$, specificity of $91.0 \%$. The area under the ROC curve was $0.91(95 \%$ confidence interval $0.80-0.97$, $\mathrm{p}=0.001)$.

Table 1: Descriptive statistics of different parameters among the controls and SLE patients:

\begin{tabular}{|c|c|c|}
\hline Variable & $\begin{array}{l}\text { SLE } \\
\text { patients }\end{array}$ & $\begin{array}{l}\text { Control } \\
\text { subjects }\end{array}$ \\
\hline Number & 31 & 30 \\
\hline Sex (Female/male) & $27 / 4$ & $25 / 5$ \\
\hline Age (years) (Mean \pm SD) & $35.1 \pm 10.3$ & $33.4 \pm 9.6^{*}$ \\
\hline Duration of diagnosis of SLE (years) (Mean \pm SD) & $4.2 \pm 2.9$ & NA \\
\hline BMI $($ Mean \pm SD) & $23.2 \pm 4.8$ & $25.3 \pm 3.2 *$ \\
\hline SLEDAI score(Mean \pm SD) & $9.4 \pm 5.2$ & $\mathrm{~A}$ \\
\hline Plasma IL 18 (pg/ml(Mean \pm SD $))$ & $222.6 \pm 66.5$ & $133.4 \pm 44.2 * *$ \\
\hline Plasma SAM(nmol/l) (Mean \pm SD) & $86.1 \pm 10.2$ & $* * 116.1 \pm 26.9$ \\
\hline Plasma SAH(nmol/l) $($ Mean \pm SD) & $34.7 \pm 7.8$ & $* * 23.8 \pm 6.9$ \\
\hline Plasma SA/SAH ratio(Mean \pm SD) & $2.65 \pm 0.94$ & $* * 5.24 \pm 1.8$ \\
\hline Plasma insulin( $\mathbf{u} U / \mathrm{ml})(\mathrm{Mean} \pm \mathrm{SD})$ & $7.6 \pm 1.5$ & $5.7 \pm 0.5 * *$ \\
\hline HOMA-IR(Mean \pm SD) & $1.9 \pm 0.3$ & $* * 1.6 \pm 0.5$ \\
\hline CIMT $(\mathrm{mm})($ Mean \pm SD $)$ & $0.89 \pm 0.42$ & $0.59 \pm 0.11 * *$ \\
\hline
\end{tabular}

Standard deviation (SD), NA (not applicable), body mass index (BMI). Systemic lupus erythematosus disease activity index (SLEDAI), Carotid intima media thickness $(C I M T) *(p>0.05), * *(p<0.001)$ 
Table 2: Correlation of plasma IL 18 with some cardiovascular risk factors and dosage of used medications in SLE patients

\begin{tabular}{lcc}
\hline \multicolumn{1}{c}{ Parameter } & $\mathbf{r}$ & $\mathbf{p}$ \\
\hline Body mass index $\left(\mathbf{K g} / \mathbf{m}^{\mathbf{2}}\right)$ & 0.45 & $\mathbf{0 . 0 1}$ \\
\hline Systolic blood pressure $(\mathbf{m m ~ H g})$ & 0.15 & 0.4 \\
\hline Diastolic blood pressure $(\mathbf{m m ~ H g})$ & 0.02 & 0.4 \\
\hline Total cholesterol (mg/dl) & 0.19 & 0.3 \\
\hline Triglycerides (mg/dl) & 0.42 & $\mathbf{0 . 0 2}$ \\
\hline HDL-C (mg/dl) & -0.34 & 0.06 \\
\hline LDL-C (mg/dl) & 0.21 & 0.3 \\
\hline Ox- LDL (EU/ml) & -0.07 & 0.7 \\
\hline Fasting plasma glucose (mg/dl) & 0.24 & 0.19 \\
\hline Fasting insulin ( ب̣U/ml) & 0.54 & $\mathbf{0 . 0 0 2}$ \\
\hline HOMA-IR & 0.52 & $\mathbf{0 . 0 0 3}$ \\
\hline HOMA- $\boldsymbol{\beta}$ & 0.24 & 0.19 \\
\hline CIMT (mm) & 0.36 & $\mathbf{0 . 0 4}$
\end{tabular}

High density lipoprotein- cholesterol, HDL-C; Low density lipoprotein- cholesterol, LDL-C; Oxidized low density lipoprotein, ox- LDL; Homeostasis model assessment insulin resistance, HOMA-IR ; Homeostasis model assessment beta cell, HOMA- $\beta$, Carotid intima media thikness (CIMT)

Table 3: Correlation between plasma IL-18 concentration and laboratory indices in patients with SLE

\begin{tabular}{|c|c|c|}
\hline Parameter & $\mathbf{r}$ & $\mathbf{p}$ \\
\hline ANA (IU/ml) & 0.6 & 0.001 \\
\hline Anti- dsDNA (IU/ml) & 0.5 & 0.008 \\
\hline $\mathrm{C3}(\mathrm{g} / \mathrm{l})$ & 0.2 & 0.3 \\
\hline $\mathrm{C4}(\mathrm{g} / \mathrm{l})$ & 0.1 & 0.6 \\
\hline ESR1 (mm/hour) & 0.56 & 0.001 \\
\hline $\mathrm{Hb}(\mathrm{gm} / \mathrm{dl})$ & 0.14 & 0.46 \\
\hline WBCs $(103 / \mu \mathrm{l})$ & 0.03 & 0.8 \\
\hline Platelets $(103 / \mu \mathrm{l})$ & 0.001 & 0.99 \\
\hline Serum creatinine (mg/dl) & 0.7 & 0.001 \\
\hline
\end{tabular}


Table 4: Correlation of plasma SAM,SAH and SAM/SAH ratio with some cardiovascular risk factors and laboratory parameters in all studied groups:

\begin{tabular}{|c|c|c|c|c|}
\hline Parameter & & $\begin{array}{l}\text { SAH } \\
(\mathrm{nmol} / \mathrm{l})\end{array}$ & $\begin{array}{l}\text { SAM } \\
(\mathrm{nmol} / \mathrm{l})\end{array}$ & $\begin{array}{l}\text { SAM/SAH } \\
\text { ratio }\end{array}$ \\
\hline Body mass index $(\mathrm{Kg} / \mathrm{m} 2)$ & ${ }^{\mathrm{r}} \mathrm{P}$ & $\begin{array}{l}0.270 \\
\mathbf{0 . 0 3 5}\end{array}$ & $\begin{array}{l}-0.119 \\
0.362\end{array}$ & $\begin{array}{l}-0.263 \\
\mathbf{0 . 0 4 1}\end{array}$ \\
\hline Systolic blood pressure (mm Hg) & $\begin{array}{l}\mathrm{r} \\
\mathrm{P}\end{array}$ & $\begin{array}{l}0.022 \\
0.907\end{array}$ & $\begin{array}{l}0.087 \\
0.641\end{array}$ & $\begin{array}{l}0.096 \\
0.606\end{array}$ \\
\hline Diastolic blood pressure (mm Hg) & $\begin{array}{l}\mathrm{r} \\
\mathrm{P}\end{array}$ & $\begin{array}{l}-0.099 \\
0.597\end{array}$ & $\begin{array}{l}0.160 \\
0.391\end{array}$ & $\begin{array}{l}0.163 \\
0.382\end{array}$ \\
\hline Total cholesterol (mg/dl) & ${ }^{r} \mathrm{P}$ & $\begin{array}{l}-0.149 \\
0.252\end{array}$ & $\begin{array}{l}0.165 \\
0.202\end{array}$ & $\begin{array}{l}0.167 \\
0.197\end{array}$ \\
\hline Triglycerides (mg/dl) & $\mathrm{r}_{\mathrm{P}}$ & $\begin{array}{l}0.457 \\
<0.001\end{array}$ & $\begin{array}{l}-0.510 \\
<\mathbf{0 . 0 0 1}\end{array}$ & $\begin{array}{l}-0.548 \\
<0.001\end{array}$ \\
\hline HDL-C (mg/dl) & $\begin{array}{l}\mathrm{r} \\
\mathrm{P}\end{array}$ & $\begin{array}{l}-0.437 \\
<0.001\end{array}$ & $\begin{array}{l}0.367 \\
0.004 \\
\end{array}$ & $\begin{array}{l}0.466 \\
<0.001\end{array}$ \\
\hline LDL-C (mg/dl) & $\begin{array}{l}\mathrm{r}_{\mathrm{P}} \\
\mathrm{P}\end{array}$ & $\begin{array}{l}-0.198 \\
0.127\end{array}$ & $\begin{array}{l}0.357 \\
0.005\end{array}$ & $\begin{array}{l}0.282 \\
0.028\end{array}$ \\
\hline Ox- LDL (EU/ml) & $\begin{array}{l}\mathrm{r} \\
\mathrm{P}\end{array}$ & $\begin{array}{l}0.309 \\
0.091\end{array}$ & $\begin{array}{l}-0.002 \\
0.993 \\
\end{array}$ & $\begin{array}{l}-0.280 \\
0.127 \\
\end{array}$ \\
\hline IL-18(pg/ml) & ${ }^{\mathrm{r}} \mathrm{P}$ & $\begin{array}{l}0.475 \\
<0.001\end{array}$ & $\begin{array}{l}-0.334 \\
\mathbf{0 . 0 0 9}\end{array}$ & $\begin{array}{l}-0.418 \\
0.001\end{array}$ \\
\hline Fasting plasma glucose (mg/dl) & $\begin{array}{l}\mathrm{r}_{\mathrm{P}} \\
\mathrm{P}\end{array}$ & $\begin{array}{l}-0.350 \\
0.006\end{array}$ & $\begin{array}{l}0.316 \\
\mathbf{0 . 0 1 3}\end{array}$ & $\begin{array}{l}0.402 \\
0.001\end{array}$ \\
\hline Fasting insulin ( $\mathbf{u} \mathrm{U} / \mathrm{ml})$ & ${ }^{\mathrm{r}} \mathrm{P}$ & $\begin{array}{l}0.029 \\
0.826\end{array}$ & $\begin{array}{l}-0.079 \\
0.545\end{array}$ & $\begin{array}{l}-0.005 \\
0.968\end{array}$ \\
\hline HOMA-IR & $\begin{array}{l}\mathrm{r}_{\mathrm{P}} \\
\mathrm{P}\end{array}$ & $\begin{array}{l}-0.210 \\
0.104\end{array}$ & $\begin{array}{l}0.146 \\
0.260\end{array}$ & $\begin{array}{l}0.262 \\
0.042\end{array}$ \\
\hline CIMT (mm) & $\begin{array}{l}\mathrm{r} \\
\mathrm{P}\end{array}$ & $\begin{array}{l}0.260 \\
0.157 \\
\end{array}$ & $\begin{array}{l}-0.038 \\
0.839 \\
\end{array}$ & $\begin{array}{l}-0.264 \\
0.151 \\
\end{array}$ \\
\hline ANA (IU/ml) & $\begin{array}{l}\mathrm{r} \\
\mathrm{P}\end{array}$ & $\begin{array}{l}0.031 \\
0.868 \\
\end{array}$ & $\begin{array}{l}-0.072 \\
0.699 \\
\end{array}$ & $\begin{array}{l}-0.089 \\
0.635 \\
\end{array}$ \\
\hline Anti- dsDNA (IU/ml) & ${ }^{r} \mathrm{P}$ & $\begin{array}{l}-0.033 \\
0.858\end{array}$ & $\begin{array}{l}0.014 \\
0.939\end{array}$ & $\begin{array}{l}0.019 \\
0.918\end{array}$ \\
\hline C3 (g/l) & $\begin{array}{l}\mathrm{r} \\
\mathrm{P}\end{array}$ & $\begin{array}{l}0.037 \\
0.842\end{array}$ & $\begin{array}{l}-0.161 \\
0.387\end{array}$ & $\begin{array}{l}-0.128 \\
0.491\end{array}$ \\
\hline C4 (g/l) & $\begin{array}{l}\mathrm{r}_{\mathrm{P}} \\
\mathrm{P}\end{array}$ & $\begin{array}{l}-0.024 \\
0.899\end{array}$ & $\begin{array}{l}-0.054 \\
0.772\end{array}$ & $\begin{array}{l}-0.022 \\
0.906\end{array}$ \\
\hline Creatinine (mg/dl) & $\begin{array}{l}\mathrm{r} \\
\mathrm{P}\end{array}$ & $\begin{array}{l}0.362 \\
0.004 \\
\end{array}$ & $\begin{array}{l}-0.259 \\
\mathbf{0 . 0 4 4} \\
\end{array}$ & $\begin{array}{l}-0.326 \\
\mathbf{0 . 0 1 0} \\
\end{array}$ \\
\hline
\end{tabular}


Table (5) Correlation of systemic lupus erythmatosus disease activity index (SLEDAI) and plasma levels of insulin, fasting plasma glucose, HOMA-IR and HOMA-B in SLE patients.

\begin{tabular}{lll}
\multicolumn{1}{c}{ Variable } & $\mathbf{r}$ & $\mathbf{p}$ \\
\hline Insulin ( $\mathbf{u} \mathbf{U} / \mathbf{m l})$ & 0.5 & $\mathbf{0 . 0 0 3}$ \\
\hline Fasting plasma glucose (mg/d) & 0.2 & 0.2 \\
\hline HOMA-IR & 0.5 & $\mathbf{0 . 0 0 3}$ \\
\hline HOMA-B & 0.22 & 0.21 \\
\hline
\end{tabular}

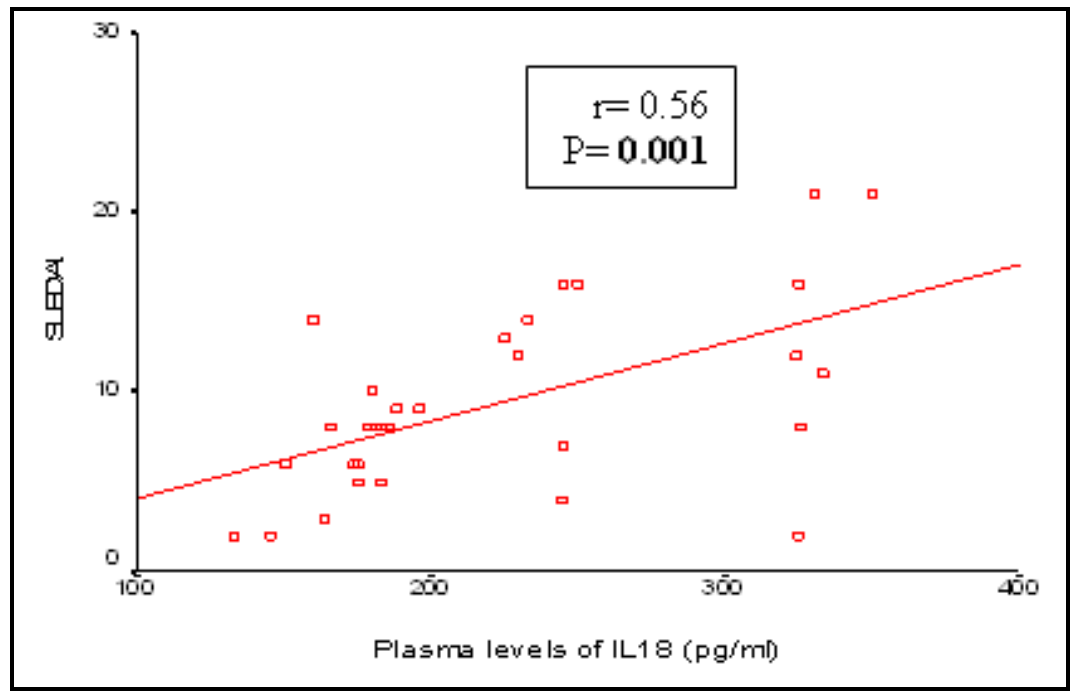

Figure 2: Correlation of plasma levels of IL 18 and systemic lupus erythmatosus disease activity index (SLEDAI) in SLE patients. 


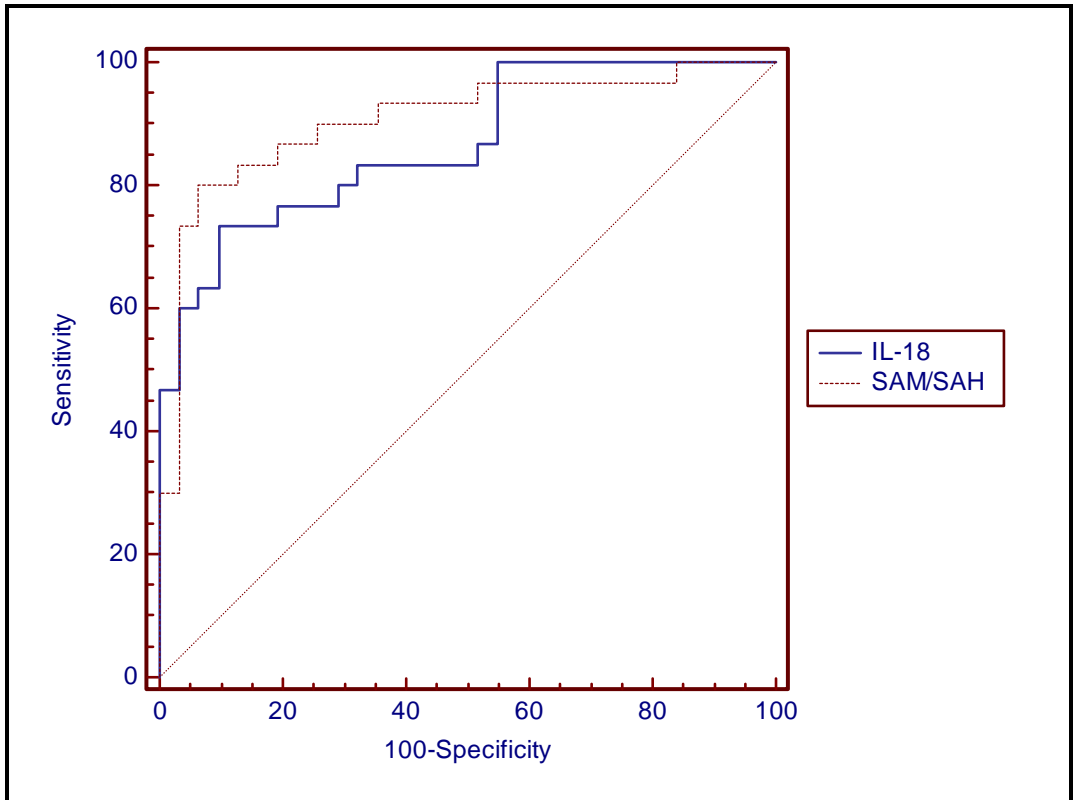

Figure 3: ROC Curve analysis of IL-18 and SAM/SAH ratio as a cardiovascular risk factors in SLE.

\section{DISCUSSION}

The incidence of SLE appears to be increasing and the main cause of death in that disease is coronary artery disease and the risk of cardiovascular disease is very high in SLE patients $^{(\mathbf{5})}$. SLE is a chronic inflammatory disease in which inflammatory and immune disease processes are likely to contribute to the accelerated atherosclerosis observed in that disease ${ }^{(\mathbf{2 1 )}}$.

The present study was designed to evaluate the relationship of interleukin 18 concentrations as well as $\mathrm{SAH}, \mathrm{SAM}$ and $\mathrm{SAM} / \mathrm{SAH}$ ratio to some traditional and non traditional cardiovascular risk factors in patients with systemic lupus erythematosus (SLE) and to evaluate their possible clinical significance with the disease activity.

In the current study, the plasma concentrations of IL-18 were elevated in SLE patients compared with healthy controls. These results agreed with those of Tso et al. ${ }^{(3)}$, Wong et al. ${ }^{(2)}$, Amerio and colleagues $^{(23)}$, Min et al. ${ }^{(24)}$, and Park et al. ${ }^{(25)}$. Elevated IL 18 concentrations in the studied patients may be related to the synergistic effects of hyperinsulinemia, insulin resistance, and impaired homocysteine metabolism, in SLE patients as reported by Tso et al. ${ }^{(3)}$.

To evaluate the correlation of IL 18 with some traditional and non traditional cardiovascular risk factors in SLE patients, the present data revealed that there was significant 
positive correlation between plasma IL-18 concentrations and body mass index. The same results were obtained by Tso et al. ${ }^{(3)}$, Esposito et al $^{(26)}$, and Hung et $\mathbf{a l}^{(27)}$. On the other hand, there were no significant correlation between IL 18 concentrations and systolic and diastolic blood pressures.

The current study addressed the question of whether plasma IL 18 levels is correlated with lipid panel in SLE patients. The study revealed that plasma IL-18 concentration positively correlated with triglycerides among those patients and there was no significant correlation with other lipid profile, however, there were no statistical difference for lipid and lipoprotein oxidations (oxiLDL) and IL-18. The same results were obtained by Tso et al. ${ }^{(3)}$. That finding suggests that elevation of plasma IL-18 levels may not enhance lipid and lipoprotein oxidations in patients with SLE.

Circulating IL-18 concentrations were also increased in insulin resistance states as in type 2 diabetes mellitus individuals compared with those in controls ${ }^{(28)}$. In the present study, we also identified positive correlations of plasma IL-18 with insulin levels and HOMA-IR in patients with SLE. These results were in accordance with the results of Tso et al. ${ }^{(3)}$. That finding suggests that elevation of plasma IL-18 may, at least in part, link inflammation with hyperinsulinemia and/or insulin resistance in SLE patients.

The measurement of SAH, SAM and calculating $\mathrm{SAM} / \mathrm{SAH}$ ratio is considered to be better biomarker of atherosclerosis than homocysteine measurement and may be causally linked to cardiovascular disease pathogenesis as reported by Liu et al. ${ }^{\text {(29) }}$ who reported that SAH is elevated in cardiovascular diseases in population with extensive atherosclerosis.

In the present study, the elevated SAH level, the decreased level of SAM and SAM/SAH ratio in SLE patients compared with the healthy controls may be related to disturbed homocysteine metabolism among those patients and hyperhomocysteinemia is evident in SLE patients. This result is in harmony with that of Petri et al. ${ }^{(30)}$ who stated that raised circulating homocysteine concentration is a risk factor for thrombotic and atherosclerotic disorders in SLE.

Homocysteine is the product of the intracellular methionine cycle, in which methionine is initially activated by ATP to $\mathrm{S}$ adenosylmethionine (SAM), the primary methyl donor for essential methyltransferase reaction. After methyl transfer, SAM is converted to $\mathrm{S}$ adenosylhomocysteine (SAH). The sole source of homocysteine in the body is the hydrolysis of SAH. The equilibrium dynamics favor the reverse reaction, the synthesis rather than the hydrolysis of SAH. Thus, elevated homocysteine concentration causes SAH accumulation ${ }^{(31)}$. Increased SAH is a potent product inhibitor of cellular methyltransferase which can alter gene expression, cell proliferation and apoptosis(32,33).Also, it may lead to product inhibition of DNA methyltransferase reactions, DNA methylation and altered gene expression $^{(34)}$.

In the current study, there was positive correlation between plasma 
SAH and IL-18 as well as plasma creatinine concentration, while, there was significant negative correlation between plasma SAM and IL-18 as well as plasma creatinine concentration. The association between elevated blood creatinine and hyperhomocysteinemia could be explained by the reduced renal clearance of homocysteine in patients with renal lupus. That finding coincides with the results obtained by Refsum et al. ${ }^{(35)} \&$ van Guldener et al. ${ }^{\text {(36) }}$ as they stated that renal function is a strong determinant of the concentration of homocysteine, and both plasma creatinine and SAH are significantly different between patients and controls.

The analysis of IL-18 and $\mathrm{SAM} / \mathrm{SAH}$ ratio has revealed both as two discriminating cardiovascular risk factors in patients with SLE versus controls with a criterion values > $157.3 \&<3.7$ respectively .These indicate that IL-18 and SAM/SAH ratio are useful biomarkers for cardiovascular risk in patients with SLE and that finding is in harmony with the results of Tso et al, ${ }^{(3)}$

In the present study, the significant increase in SLE patients than in control subjects, and its positive correlation of IL-18 with CIMT may indicate that IL-18 may be involved in the development of vascular stiffness in patients with SLE. The same result was obtained by Leeuw et al. ${ }^{(37)}$ and Colombo et al. ${ }^{(38)}$ who found that CIMT was higher in SLE patients than controls.

In the present work, the negative correlation between SAM/SAH ratio with IL-18 and CIMT is an indicators that hyperhomocysteinemia was associated with increased secretion of IL-18 and increased thickness of the wall of carotid artery and these coincides with the result of Aso et al. ${ }^{(39)}$ who found the same results in patients with type 2 diabetes. They explained their finding by the fact of increased plasma concentration of homocysteine may likely to stimulate IL-18 secretion by monocytes and macrophages.IL-18 is a proatherogenic cytokine associated with the development of cardiovascular disease as it is demonstrated that its expression is increased in human atherosclerotic plaques in associatation wih plaque destabilization $^{(40)}$.

Plasma homocysteine could be considered as an independent risk factor for the increased carotid artery wall thickness ${ }^{(41-43)}$, so, plasma homocysteine and IL-18 may contribute to the increased CIMT observed in the present study and such finding coincides with those of Aso et al. ${ }^{(39)}$ who reported the same finding in type 2 diabetes and postulated many mechanisms for homocysteine induced vascular disease as endothelial dysfunction ${ }^{(44)}$, smooth muscle $\quad$ proliferation $^{(45)}$, hypercoagulation $^{(46)}$ and inflammatory plaque instability mediated by the elevated !L-18 ${ }^{(39)}$

To evaluate the relation of IL 18 to SLEDAI, the current study demonstrated that there was a significant positive correlation between IL-18 concentration and SLEDAI score in SLE patients. These results are compatible with previous studies $^{(\mathbf{3}, \mathbf{2 2 - 2 5})}$. This indicates that IL18 can enhance the expression of Fas ligand in natural killer cells and 
cytotoxic T lymphocyte, causing Fasmediated apoptosis in epithelial cells and tissue damage ${ }^{(47)}$. So, the elevation of IL-18 might therefore be crucial for organ damage in the exacerbation of SLE. On the other hand, Robak and colleagues ${ }^{(4)}$ found no correlation between IL-18 concentrations and disease activity. This contradiction with the current results may be related to different race, number and different laboratory assay in the studied subjects.

In the present study, there were significant positive correlation between plasma IL 18 concentrations and ANA, Anti dsDNA, ESR1 and plasma creatinine. These results are in accordance with those of Min et al. ${ }^{\text {(24) }}$. This finding suggests that the elevation of pro-inflammatory cytokine IL-18 may trigger the inflammatory process in SLE

The concentrations of plasma IL18 in SLE patients with elevated plasma creatinine were significantly higher than those with normal plasma creatinine in the present study. The same results was obtained by Wong et $\mathrm{al}^{(48)}$, and these results suggested that IL 18 may play a role in the inflammatory processes of renal disease in SLE.

In the present work, the mean plasma levels of insulin and HOMAIR was significantly higher in SLE patients than in the control subjects and there were positive correlations between SLEDAI and both plasma levels of insulin and HOMA-IR values. The same results were obtained by Tso et al. ${ }^{(49)}$. Elevation of both plasma insulin and insulin resistance index will trigger the endothelial dysfunction and subsequent atherosclerotic process. So, the elevation of fasting insulin levels in SLE patients is not only associated with insulin resistance, but is also related to disease activity, classic and novel cardiovascular risk factors and this may explain the insulin-related cardiovascular disease risk in SLE ${ }^{\mathbf{5 0})}$.

From the present results, it could be concluded that plasma IL-18 in patients with SLE may be associated with increases in fasting insulin levels, HOMA-IR and homocysteine. Also, among SLE patients, the high level of IL-18 reflects activity of the disease and is related to cardiovascular risk factors.

The synergistic effects of hyperinsulinemia, insulin resistance, hyperhomocysteinemia, and elevation of plasma IL-18 concentrations will trigger the endothelial dysfunction and subsequent atherosclerotic pathogenic process. On the other hand, $\mathrm{SAM} / \mathrm{SAH}$ ratio might be a new marker for cardiovascular risks in SLE . Also, suppression or antagonism of IL-18 might be beneficial as a new strategy for therapy in that disease..

Acknowledgements: The authors would like to thank all of the patients included in the work.

\section{REFERENCES}

1. Gabor G, Tackey IE, Lapteva L and Lipsky PE (2004): Biomarkers in systemic lupus erythematosus: Markers of disease activity. Arthritis and rheumatism 50, (7): 2048-65.

2. Ward MM (1999): Premature morbidity from cardiovascular 
and cerebrovascular diseases in women with systemic lupus erythematosus. Arthritis Rheum., 42:338-46.

3. Tso $\mathbf{T}$ K,Huang WN, Huang HY and Chang CK (2006): Relationship of plasma interleukin-18 concentrations to traditional and non-traditional cardiovascular risk factors in patients with systemic lupus erythematosus. Rheumatology 45(9):1148-1153 .

4. Robak E, Robak T, Wozniacka A, Zak-Prelich M, SysaJedrzejowska A, Stepien H (2002): Proinflammatory interferon-inducing monokines (interleukin-12, interleukin-18, interleukin-15): serum profile in patients with systemic lupus erythematosus. Eur. Cytokine Netw .,13: 364-368.

5. Frostegård J (208): Systemic lupus erythematosus and cardiovascular disease. Lupus 17(5): 364-67.

6. Dayal S, Bottiglieri T,Arning E, Maeda N, M.Malinow R, Sigmund CD, Heistad DD, araci FM, and Lentz SR (2001): Endothelial Dysfunction and Elevation of $\mathrm{S}$ Adenosylhomocysteine in Cystathionine b-SynthaseDeficient Mice. Circ. Res., 88:1203-1209.

7. Refai TMK, Al-Salem IH, Nkansa-Dwamena D, Al-Salem MH (2002): Hyperhomocysteinemia and risk of thrombosis in systemic lupus erythematosus patients. Clin. Rheumatol., 21:457-461.
8. Tan EM, Cohen AS, Fries JF, Masi AT, McShane DJ, Rothfield NF, Schaller JG, Talal $\mathbf{N}$ and Winchester RJ (1982): The 1982 revised criteria for the classification of systemic lupus erythematosus. Arthritis Rheum., 25:1271-1277.

9. Bomberdier C, Gladman D, Urowitz M, Caron D, and Chang CH (1992): The Committee on Prognosis Studies in SLE: derivation of the SLEDAI. A disease activity index for lupus patients. Arthritis Rheum .,35:630-640.

10. Daniel $S$ and Channing $R$ (1991): Clinical laboratory methods for detection of antigen and antibodies. In Clinical and Basic Immunology 1991;. Daiel PS and Abba T (eds). Prentice, Hall International, Mexico, London, Sydney, 566-8.

11. Rubin RL (1986): Enzyme linked immunosorbent assay for anti DNA. In Manual of clinical laboratory immunology; Rose NR, Fredman $\mathrm{H}$ and Fahey J (eds). Saunders company, Philadelphia, 744-6.

12. Quchterlony $O$ and Nillson LA (1986): Immunodiffusion and immunoelectrophoresis. In Handbook of experimental immunology1986; Wein D (eds). $1^{\text {st }}$ edition, volume 1 , Blackwell Scientific Publisher, Oxford, 5253.

13. Okamura H .,Tssti H ,Komatsu T, Yutsudo M,hakura A,Tanimoto T,Torigoe K,Okura T, Nukada $Y$ and Hattori K (1995): Cloning of new cytokines that induces INF $\gamma$ 
production by $\mathrm{T}$ cells. Nature 378(6552):88-91.

14. She Q.B, Nagao I, Hayakawa T, and Tsuge $H$ (1994): A simple HPLC method for the determination of Sadenosylmethionine and $\mathrm{S}$ adenosylhomocysteine in rat tissues: the effect of vitamin B6 deficiency on these concentrations in rat liver. Biochem. Biophys. Res. Commun., 205:1748-1754

15. Matthews DR, Hosker JP, Rudenski AS, Naylor BA, Treacher DF, Turner RL (1985): Homeostasis model assessment: insulin resistance and ß-cell function from fasting plasma glucose and insulin concentrations in man. Diabetologia 28:412-419.

16. Allian CC (1974): Determination of total cholesterol. Clin.Chem ., 20:470.

17. Wahlefeld AW (1974): Triglyceride determination after enzymatic hydrolysis. In: H.V.Bergmger (ed). Method of enzymatic analysis; 2nd.English eds: Acad.Press,Inc. New York London.Vol4:pp1831

18. Lopeo-Virella, M.F., Stone, P.G. and Colwell, J.A. (1977): Cholesterol determination in high density lipoproteins separated by three different methods. Clin. Chem .,23:882.

19. Friedewald WT, Levy RI, Fredrickson DS (1972): Estimation of the concentration of low-density lipoprotein cholesterol in plasma without use of the preparative ultracentrifuge. Clin. Chem ., 18:499-502.
20. Pignoli P, Tremoli E, Poli A, Oreste P, Paoletti R (1986): Intimal plus medial thickness of the arterial wall: a direct measurement with ultrasound imaging. Circulation 74:13991406.

21. Manzi S: Systemic lupus erythematosus (2000): a model for atherogenesis? Rheumatology 39:353-359.

22. Wong CK, Li EK, Ho CY, Lam CW (2000): Elevation of plasma interleukin-18 concentration is correlated with disease activity in systemic lupus erythematosus. Rheumatology 39: 1078-1081.

23. Amerio P, Frezzolini A, Abeni D, Teofoli P,Girardelli CR ,De Pita $O$ and Puddu P(2002): Increased IL-18 in patients with systemic lupus erythematosus: relations with Th-1, Th-2, proinflammatory cytokines and disease activity: IL-18 is a marker of disease activity but does not correlate with pro-inflammatory cytokines. Clin. Exp.Rheumatol., 20(4): 535-538.

24. Wong Ck, Li EK,Ho CY and Lam CWK L(2004): Elevated interleukin-18 levels is correlated with disease activity in systemic lupus erythematosus. Rheumatology 39:1078-1081.

25. Park MC, Park YB, Lee SK (2004): Elevated interleukin-18 levels correlated with disease activity in systemic lupus erythematosus. Clin. Rheumatol .23:225-9.

26. Esposito K, Nappo F, Giugliano F, Palo CD,Ciotola M,Barbieri M,Paolisso $G$ and Giugliano D (2003): Cytokine milieu tends 
toward inflammation in type 2

diabetes. Diabetes Care

26(5):1647.

27. Hung J, McQuillan BM, Chapman CML, Thompson PL, Beilby JP (2005): Elevated interleukin-18 levels are associated with the metabolic syndrome independent of obesity and insulin resistance. Arterioscler.Thromb. Vasc. Biol ., 25:1268-73.

28. Mahmoud RA, el-Ezz SA, Hegazy AS (2004): Increased serum levels of interleukin-18 in patients with diabetic nephropathy. Ital. J.Biochem .,53:73-81.

29. Liu C, Wang Q, Guo H, Xia M, Yuan Q, Hu Y, Zhu H, Hou M, Ma J, et al. (2008): Plasma Sadenosylhomocysteine is a better biomarker of atherosclerosis than homocysteine in apolipoprotein E-deficient mice fed high dietary methionine. J. Nutr. ,138:311-5.

30. Petri M,Roubenoff R,Dallal GE, Nadeau MR, Selhub J, Irwin $\mathbf{H}$, and Rosenberg JH (1996): Plasma homocysteine as a risk factor for atherothrombotic events in systemic lupus erythematosus .Lancet 348:11201124.

31. Yi P, Melnyk S, Pogribna M, Pogribny IP, Hine RJ, James SJ (2000): Increase in plasma homocysteine associated with parallel increases in plasma Sadenosylhomocysteine and lymphocyte DNA hypomethylation. J. Biol. Chem., 275:29318-23.

32. Ehrlich M.(2003): Expression of various genes is controlled by
DNA methylation during mammalian development. J.Cell Biochem.,88: 899-910.

33. Finnell RH, Spiegelstein O, Wlodarczyk B, Triplett A, Pogribny IP, Melnyk S and James JS (2002): DNA methylation in Folbp1 knockout mice supplemented with folic acid during gestation. J. Nutr., 132(8 suppl.): 2457S-61S.

34. Perna AF, Ingrosso D, Lombardi C, Acanfora A, Satta E, Cesare CM, Violetti E, Romano MM and De Santo N: (2003) Possible mechanisms of homocysteine toxicity. Kidney International 63, S137-S140

35. Refsum $H$, Ueland PM, Nygard O, Vollset SE (1998): Homocysteine and cardiovascular disease. Annu. Rev. Med.,49:3162.

36. van Guldener C, Donker AJM, Jakobs C, Teerlink T, deMeer K, Stehouer CD(1998): No net renal extraction of homocysteine in fasting humans. Kidney Int.,54:166-9.

37. Leeuw KD, Freire B, Smit A J , Bootsma $\mathbf{H}$, Kallenberg $\mathbf{C} \mathbf{G}$, Bijl M (2006): Traditional and non-traditional risk factors contribute to the development of accelerated atherosclerosis in patients with systemic lupus erythematosus. Lupus 15(10): 675-82.

38. Colobo BM,Cacciapaglia F,Puntoni M,Murdaca G,Rossi E,Rodriguez G,Nobili F,Pisciotta L,Bertolini S,Moccetti T,Dentali F,Steidl L,Ciprandi G,Afeltra 
A,Indiveri $F$ and Puppo F(2008): Traditional and nontraditional risk factors in accelerated atherosclerosis in Systemic Lupus Erythematosus: Role of vascular endothelial growth factor (VEGATS Study). Autoimmun. Rev .,4:309-15.

39. Aso Y, Okuumura KI, Takebayashi K, Wakabayashi $S$ and Inukai $T$ (2003): Relationships of Plasma Interleukin-18 Concentrations to Hyperhomocysteinemia and Carotid Intimal-Media Wall Thickness in Patients With Type 2 Diabetes. DIABETES CARE 26(9):2622-2627.

40. Mallat Z, Corbaz A, Scoazec A, Besnard S, Leseche G, Chvatchko $Y$ and Tedgui $A$ (2001): Expression of interleukin18 in human atherosclerotic plaques and relation to plaque instability. Circulation 104:15981603.

41. Selhub J, Jacques PF, Bostom AG, D'Agostino RB, Wilson PW, Belanger AJ, O'Leary DH, Wolf PA, Schaefer EJ and Rosenberg IH (1995): Association between plasma homocysteine concentrations and extracranial carotid-artery stenosis. N. Engl. J. Med., 332:286-291.

42. McQuillan BM, Beilby JP, Nidorf M, Thompson PL and Hung J (1999): Hyperhomocysteinemia but not the C677T mutation of methylene tetrahydrofolate reductase is an independent risk determinant of carotid wall thickening: the Perth Carotid Ultrasound Disease
Assessment Study (CUDAS).

Circulation 99:2383-2388.

43. Adachi H, Hirai Y, Fujiura Y, Matsuoka $H$, Satoh $A$ and Imaizumi $T$ (2002): Plasma homocysteine levels and atherosclerosis in Japan: epidemiological study by use of carotid ultrasonography. Stroke 33:2177-2181.

44. van Guldener $C$ and Stehouwer CD (2000): Hyperhomocysteinemia, vascular pathology, and endothelial dysfunction. Semin. Thromb. Hemost., 26:281-289.

45. Tsai JC, Perrella MA, Yoshizumi M, Hsieh CM, Haber E, Schlegel $R$ and Lee ME (1994): Promotion of vascular smooth muscle cell growth by homocysteine: a link to atherosclerosis. Proc. Natl.Acad. Sci .U S A 91: 6369-6373.

46. Lentz SR, Piegors DJ, Fernandez JA, Erger RA, Arning E, Malinow MR, Griffin JH, Bottiglieri T, HaynesWG and Heistad DD (2002): Effect of hyperhomocysteinemia on protein $\mathrm{C}$ activation and activity. Blood 100:2108-2112.

47. Dinarello CA (1997): Role of pro- and anti-inflammatory cytokines during inflammation: experimental and clinical findings. J. Biol. Regul. Homeost. Agents 11:91-103.

48. Wong, CK, HO CY, Li EK, Tam LS, Lam CWK (2002): Elevated production of interleukin-18 is associated with renal disease in patients with systemic lupus erythematosus. 
Clinical and Experimental Immunology 130(2):345-51.

49. Tso T K, Huang, W-N, Huang, H-Y, Chang, C-K (2006a): Elevation of plasma interleukin18 concentration is associated with insulin levels in patients with systemic lupus erythematosus. Lupus 15(4): 20712.
50. Esdaile JM, Abrahamowicz M, Grodzicky T, Li Y, Panaritis C, du Berger R, Cote R, Grover SAFortin PR, Clarke AE and Senecal JL (2001): Traditional Framingham risk factors fail to fully account for accelerated atherosclerosis in systemic lupus erythematosus. Arthritis Rheum., 44(10): 2331-7. 


\section{دور الانترلوكين-1 1؛ إس أدينوزيل ميثيونين؛ إس أدينوزيل هوموسيستين كعوامل خطورة للقب والأوعية الدموية لدى مرضى الدين الأئبة الحمراء الجهازية}

أبين السدنودى* ـ عادل زلطه* ـ عبد الحمبي متولى ـ فايز القناوى- عادل الببراوى**

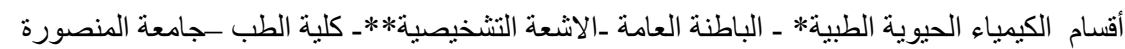

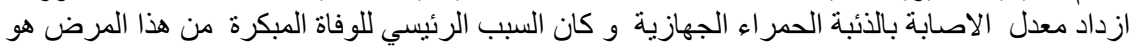

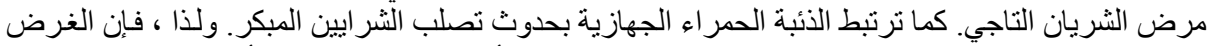

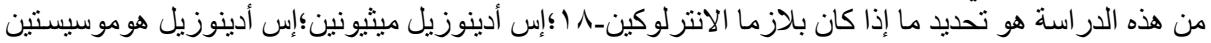

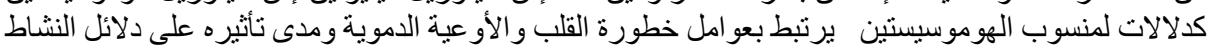
المرضى فى مرضى الذئبة الحمر اء الجهازية.

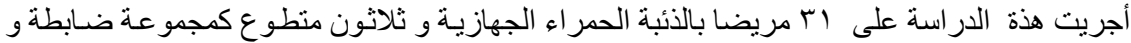

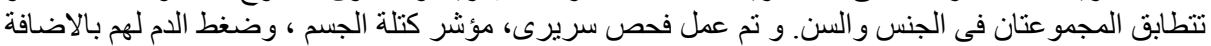

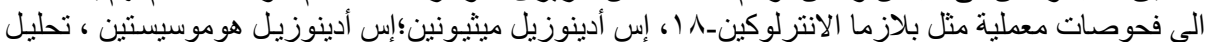

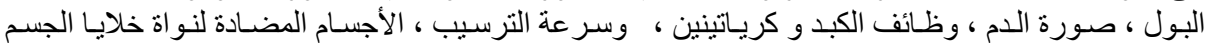

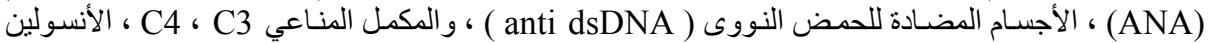

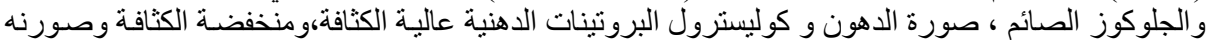

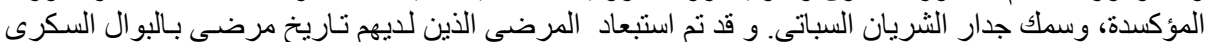

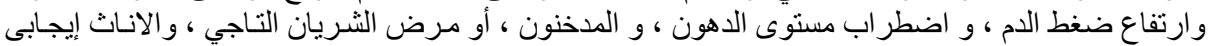

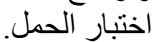

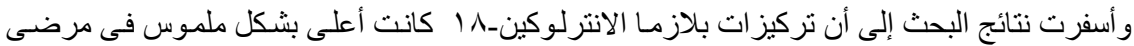

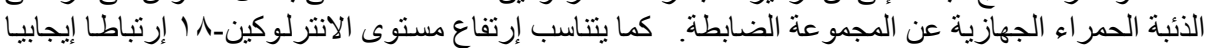

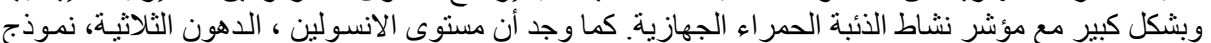

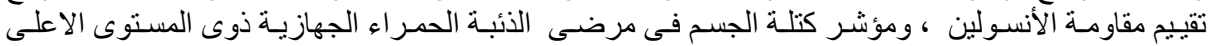

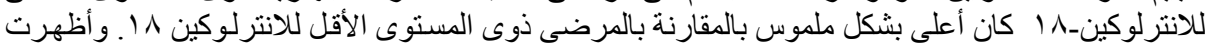

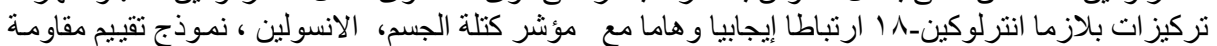

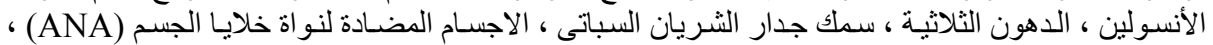

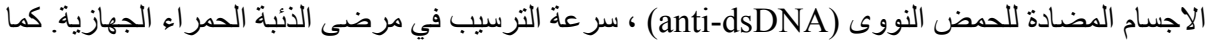

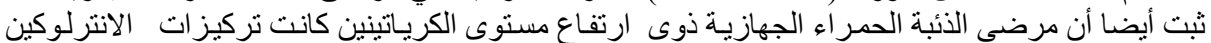

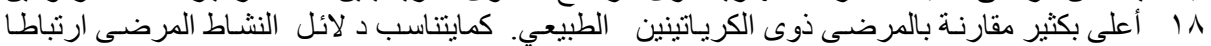

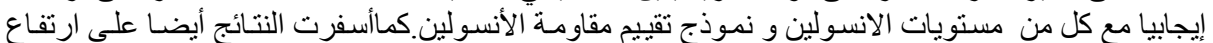

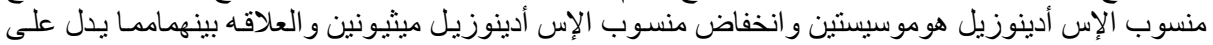

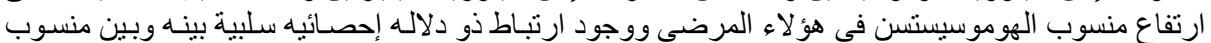

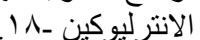

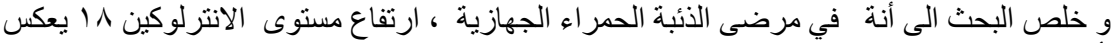

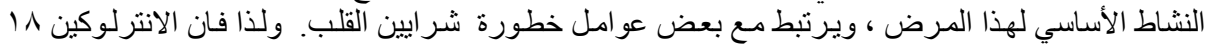

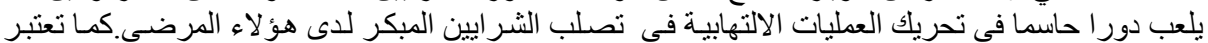

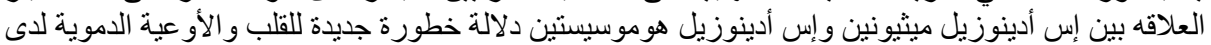

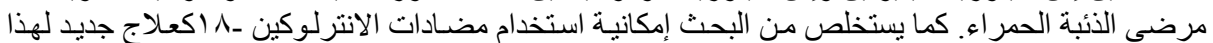
المرض. 